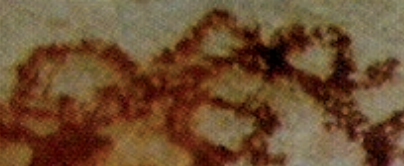

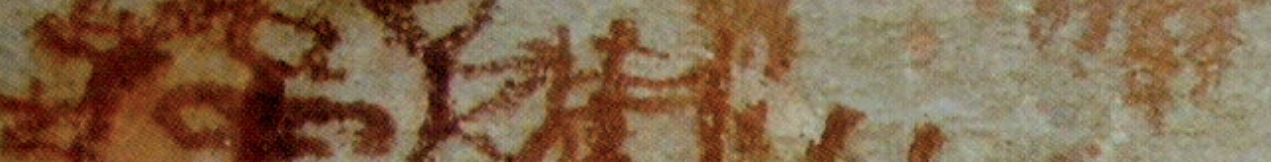

(5) 52

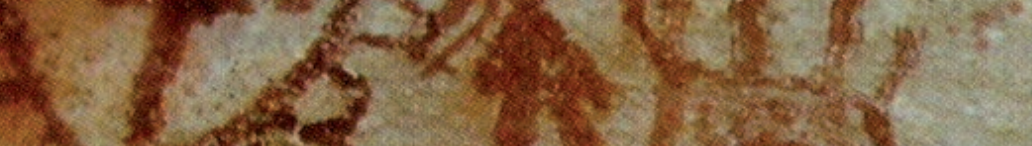

(1)

का 13

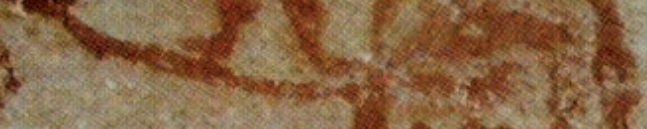
1 $2 x^{2}$

heri 1 10035

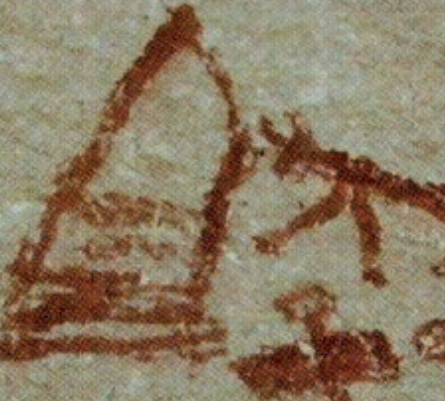

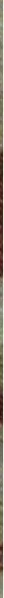

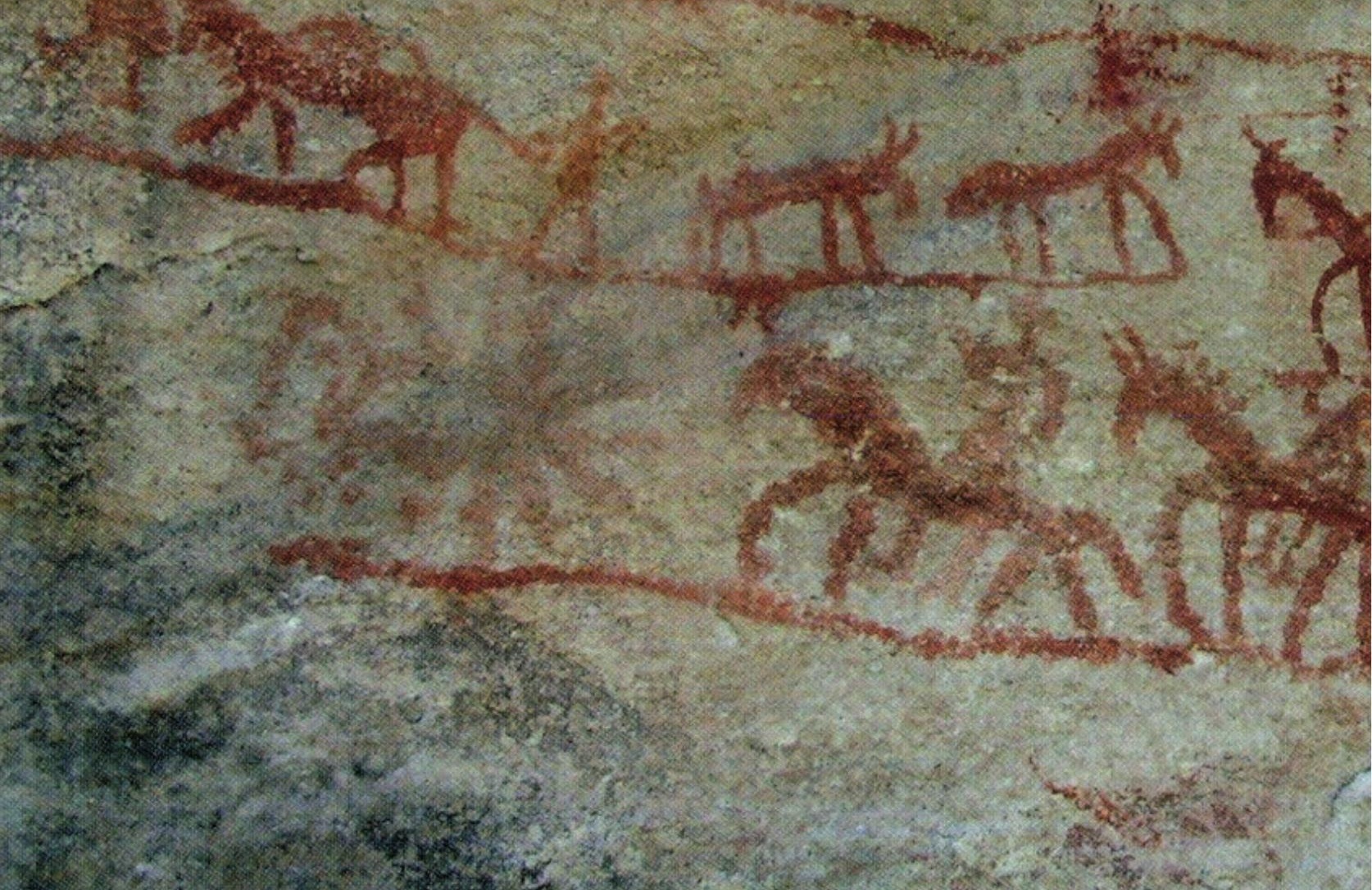

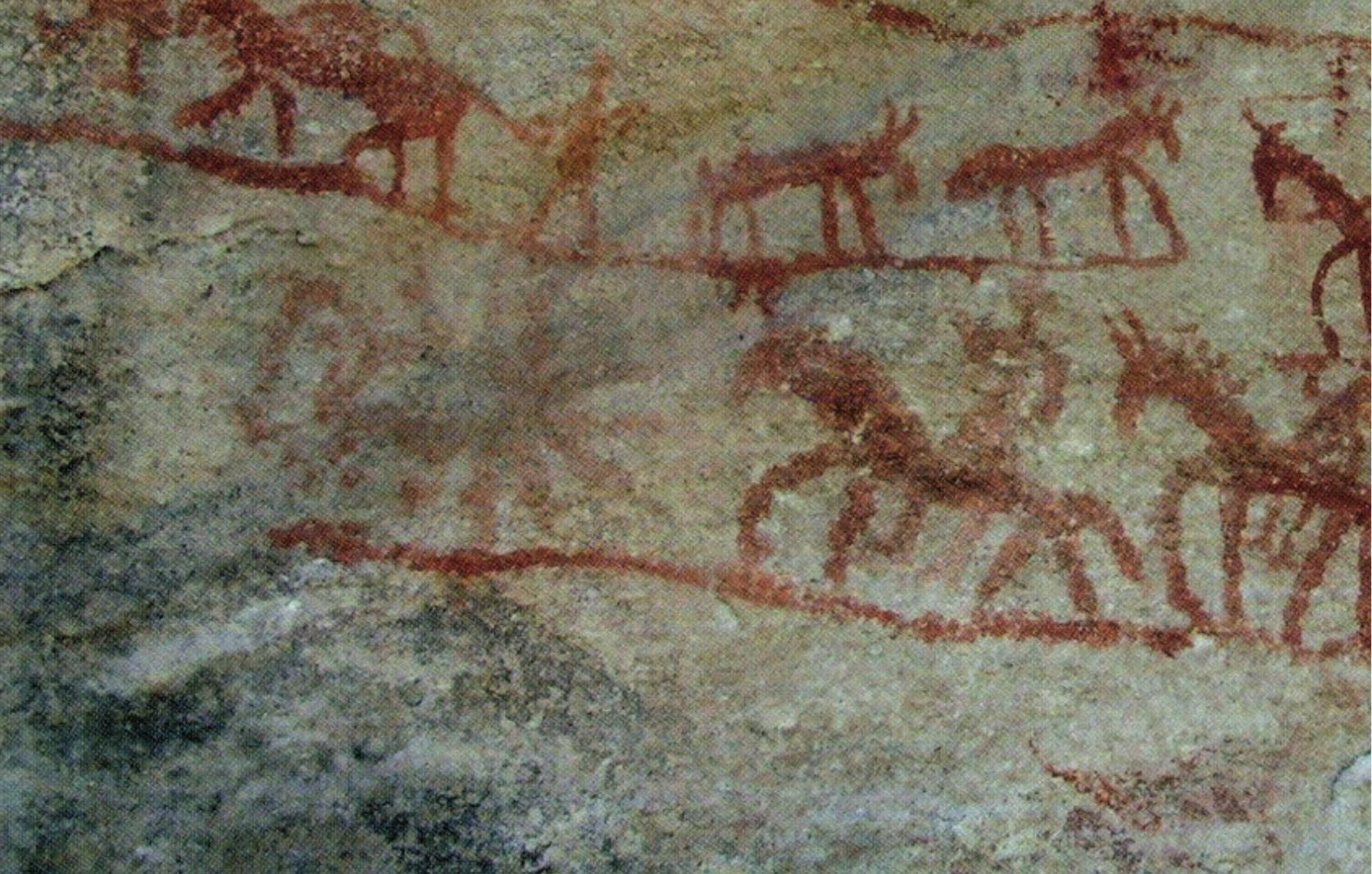




\title{
La alegoría de Santiago Apóstol una muestra de arte rupestre colonial en la cordillera puneña
}

Roberto Guillermo Ramos Castillo

Universidad Nacional del Altiplano ramoscastilloroberto25@gmail.com

\begin{abstract}
Resumen
Las investigaciones sobre el arte rupestre de la cuenca del lago Titicaca han tomado un inusitado interés debido a las recientes experiencias de catalogación realizadas en las tres ecozonas de la región Puno -Cordillera, Altiplano y Amazonia- las que, a su vez, han reportado nuevos sitios con este tipo de representaciones parietales, pertenecientes todas al periodo prehispánico y específicamente al arcaico. El presente trabajo analiza, sin embargo, uno de los escasos ejemplos de arte rupestre del periodo colonial de la región, específicamente aquel relacionado con la iconografía y los atributos del Apóstol Santiago El Mayor.
\end{abstract}

Palabras clave: Arte rupestre, cruz, espada, iconografía, Santiago Apóstol

\begin{abstract}
Research of rock art in the Lake Titicaca basin in recent years have taken an unusual interest. Due to recent cataloguing experiences of study in the three Eco zones in the region of Puno: Mountain range, highland and Amazonia, which in time have reported new sites with this type of frescos representations - assigned chronologically to the pre-Hispanic period and, associated with archaic. However, this work, one of the few examples of rock art of the colonial period in the region, specifically related with the iconography and the attributes of Apostle James the Greater.
\end{abstract}

Keywords: rock art, cross, sword, iconography, Apostle James

\section{I.- Ubicación del panel rupestre}

El altiplano puneño se ubica en el extremo sur y hacia el este de la República del Perú. La geografía física de la meseta del Collao y el escarpado de ladera y cima cordillerana que encierra la cuenca endorreica del Titicaca, pareciera idónea para pintar o labrar arte rupestre. La sierra presenta características fisiográficas peculiares y distintas, que determinan la topografía, el clima y la vocación productiva. Utilizando el concepto de regiones naturales de Pulgar Vidal se puede subdividir en dos zonas ecológicas la sierra collavina: la región Suni, ubicada entre los 3,500 y los 4,000 msnm, cuyo clima frío y termorregulado por la influencia del lago determina su gran potencial agrícola y en donde se localizan los principales asentamientos humanos. Y la región Puna, ubicada entre los 4,000 y 4,800 msnm, 


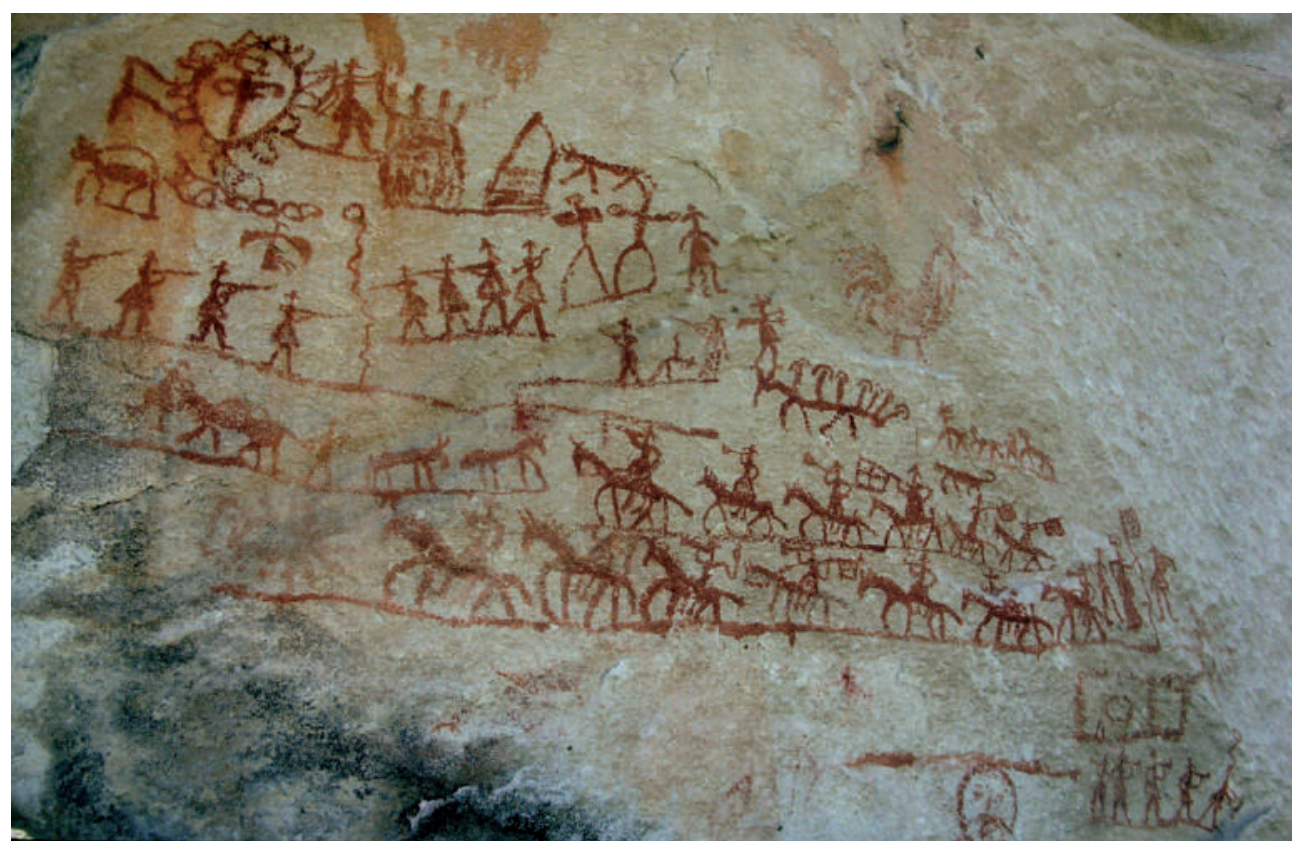

Fig.1. Panel rupestre Alegoría de Santiago Apóstol, sobre toba volcánica.

cuyo clima oscila entre frígido y glacial, y en donde miles alpacas y llamas se alimentan de sus pastos duros. Es en este piso ecológico donde se encuentran las representaciones rupestres (Pulgar, 1996:97-114).

La población aledaña identifica el sitio que vamos a analizar como peñón de Ccanccahuani (quechua) el cual está ubicado en la provincia de Carabaya, distrito de Corani, comunidad campesina de Quelcaya. En términos de geo referencia compromete las coordenadas UTM. WGS84: $318186 \mathrm{E}-8457854 \mathrm{~N}$, con una altitud de 4,558 msnm de la carta nacional, hoja 28 -v. El tipo de roca es toba volcánica-formación Quenamari, miembro Yapamayo (Chávez et al, 1997:63-64).

\section{II.- Descripción del sitio rupestre}

El siguiente texto de Teresa Gisbert nos introduce en el tema central de este artículo:

Fuera de la identificación de María con la Madre Tierra, está la identificación de Santiago con Illapa. Arriaga dice que Cristo Nuestro Señor llamó "rayos a Santiago y Juan que esto quiere decir hijos del Trueno. La identificación con el rayo (libiac o Illapa) resulta pues de la frase evangélica. Arriaga supone que la identificación se realiza porque los muchachos españoles solían decir, cuando tronaba, que "corría el caballo de Santiago" o de que los españoles al disparar el arcabuz solían gritar "Santiago" (...) en la Iglesia de Triunfo en Cusco en la lápida se indica: Fue visto salir el Patrón de las Españas Santiago...y atónita la idolatría veneró Rayo al Hijo del Trueno (Gisbert, 2004:28).

El sitio está constituido por un peñón o promontorio rocoso de origen volcánico de aproximadamente 25 metros de altura en cuya parte inferior se encuentra el panel de unos tres metros de ancho por un metro de altura. Técnicamente se trata de una pintura de color rojo sobre roca, la cual, temáticamente, nos induce a titularla como "La alegoría de Santiago Apóstol” y a situarla cronológicamente entre los primeros años de la presencia 
española y el siglo XVII. Su estilo es naturalista aunque cuenta con algunos motivos esquematizados. Su autor es desconocido (fig.1).

\section{a.- Motivos identificados}

Cruz de Santiago o Cruz-espada de la Orden Militar de los Caballeros de Santiago, jinetes, arcabuceros, trompeteros, banderas, estandartes, figuras geométricas, figuras zoomorfas y descontextualizadas.

\section{b.- Análisis iconográfico, significado convencional}

El texto iconográfico desarrolla, como fondo, la estructura panorámica de un cerro y los elementos que lo ocupan y "trepan" imponen una sensación de movimiento ascensional a través de siete niveles o curvas de nivel. En la cumbre del collado, es decir, en el lugar más prominente y de donde se domina la escena, se ha pintado el símbolo de la Cruz o la espadilla de la orden militar de los Caballeros de Santiago dentro de un medallón con ornamentos en el borde. Inmediatamente debajo está presente un hombre y una suerte de altar festivo-religioso con equinos descontextualizados. En el curso medio de la pendiente cerril destacan dos columnas frente a frente: cada una de cuatro arcabuceros, vestidos a la usanza de los militares españoles del siglo XVII, con sombrero de ala ancha y casaca-chaqueta larga. Más abajo, en una ladera con poco declive, dos hombres arrean acémilas. Finalmente en las faldas del vértice rocoso se lucen en desfile marcial dos columnas de jinetes: unos tocan trompetas, otros portan banderas y un último, a pie, sostiene un estandarte. Esta obra rupestre que hemos denominado "La alegoría de Santiago Apóstol" representa una escena compleja en la que cabe una lectura simbólica pormenorizada (fig.2).

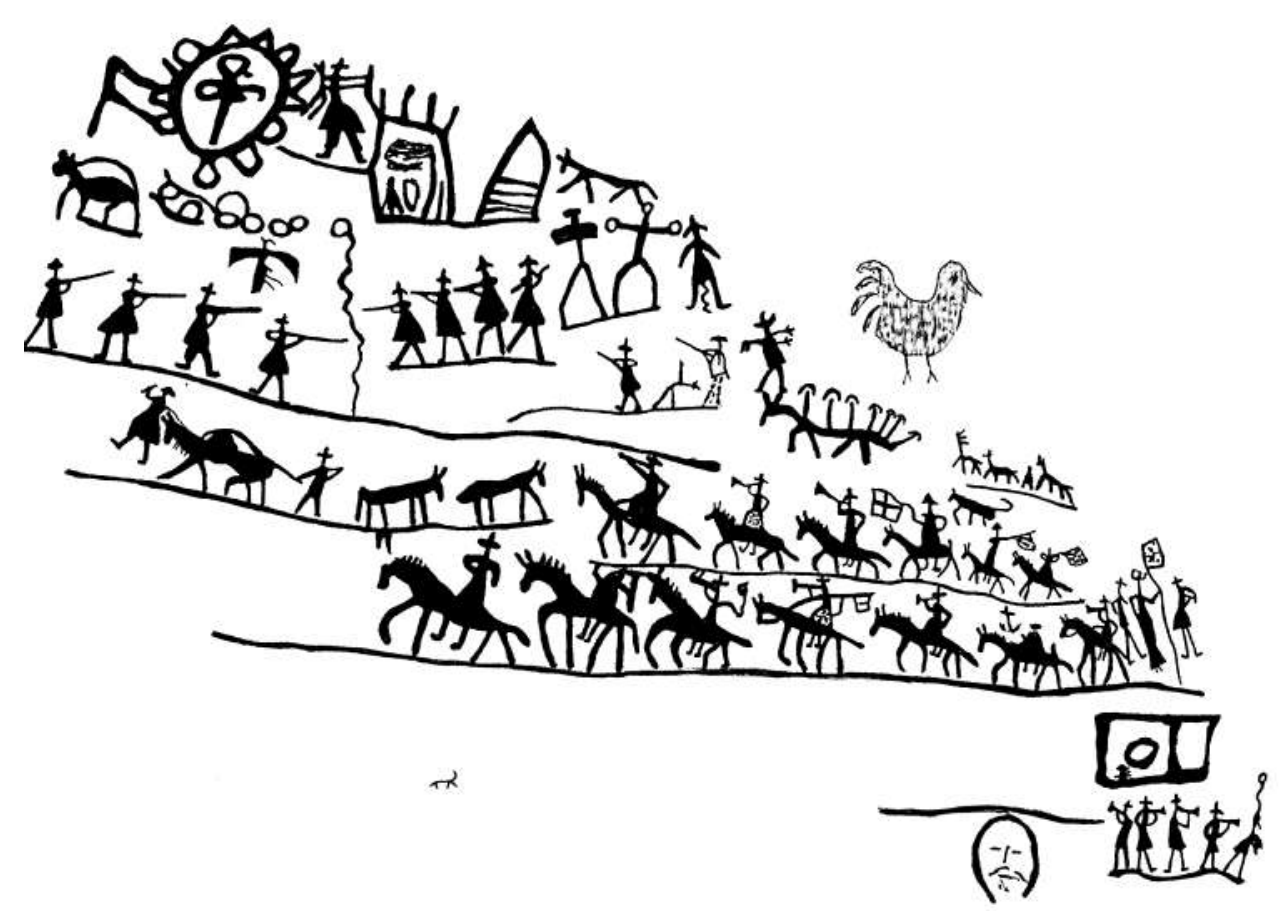

Fig.2. Dibujo de Nicolás Peralta. Tomado de Rainer Hostning. 
La representación de la Cruz de Santiago Apóstol o de la Orden de los Caballeros de Santiago, es un tema reiterado en la iconografía colonial andina: podemos verla en pinturas al óleo, en esculturas y, fundamentalmente, labrada en frontispicios de templos coloniales, que en algunos casos están advocados al Santo patrón español, como por ejemplo en la ciudad de Lampa o Santiago de Pupuja (fig.3) o, por citar uno más opulento, en la fachada lateral del templo de la Compañía en Arequipa (fig.4). De igual modo la Cruz de Santiago podemos identificarla independientemente, como escudo nobiliario o como elemento en la vestimenta y estandartes de Santiago de la batalla de Clavijo ${ }^{1}$. Lo concreto es que la presencia central y subrayada de este atributo iconográfico permite caracterizar, de forma

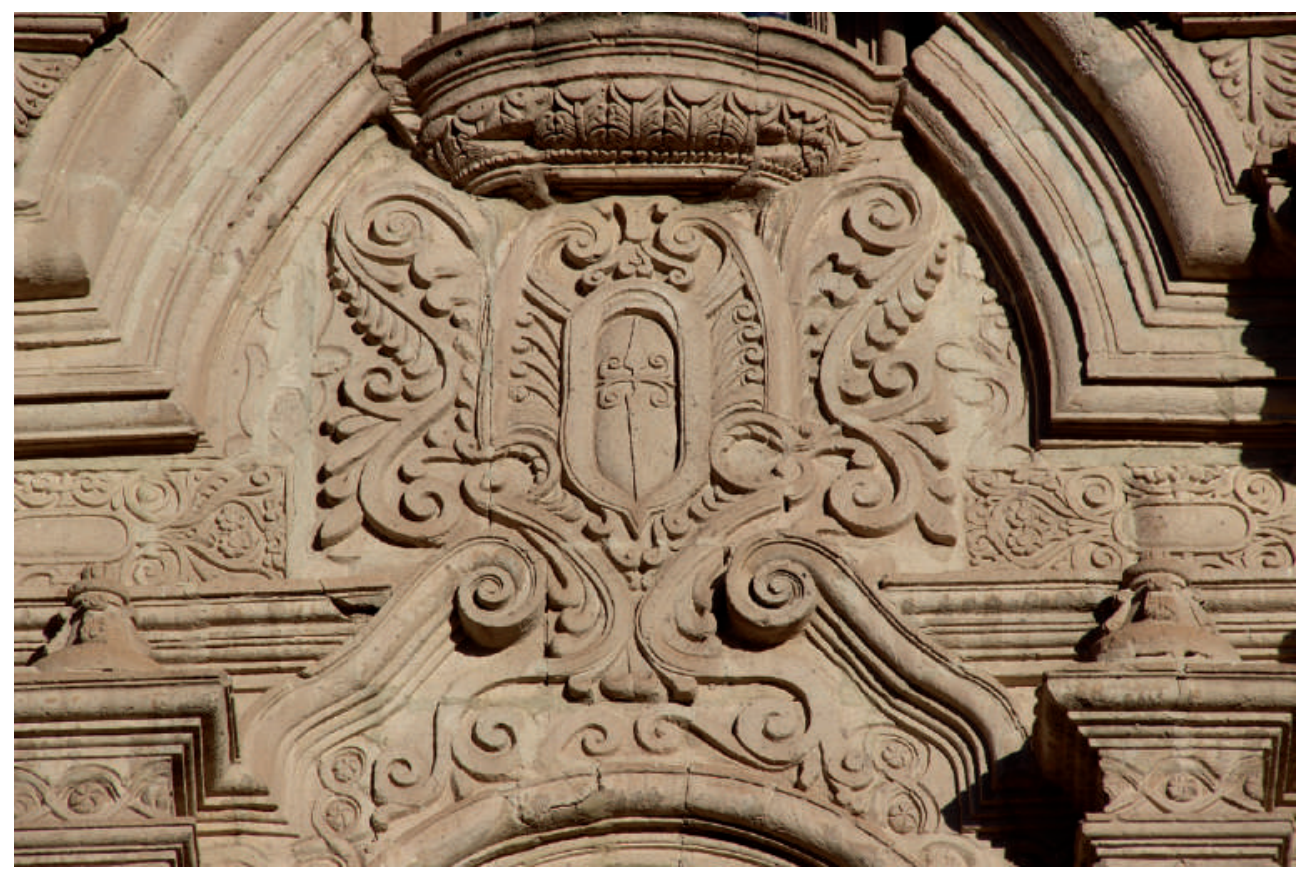

Fig.3. La espadilla de Santiago en el frontis del templo "Santiago Apóstol" en la ciudad de Lampa-Puno.

precisa, la identidad de la figura representada, es decir, el Apóstol Santiago del Mayor. Los demás elementos, como jinetes con banderas o estandartes, trompeteros y arcabuceros, así como animales, entre los cuales reconocemos un cóndor con las alas extendidas, un zorro o cánido de perfil y, finalmente, un trazo geométrico -aparentemente un altar- son motivos secundarios.

Tal como hemos dicho, el programa iconográfico, en general, hace referencia a la alegoría de Santiago Apóstol. La Cruz es la personificación del Apóstol Santiago, el santo que milagrosamente se apareció en la batalla de Clavijo durante el proceso de la reconquista española y la expulsión de los musulmanes y el símbolo de Cruz-espada es la señal de los caballeros de la orden militar de Santiago. Los motivos pintados que configuran el corpus del panel, es decir jinetes, trompetas, banderas, estandartes y arcabuceros, nos remiten directamente a esa faceta mítica y asombrosa que fue muy bien utilizada por los españoles

1 Fue un enfrentamiento que se consideró durante mucho tiempo como una de los más celebres batallas de la Reconquista, dirigida por el rey Ramiro I contra los musulmanes. Se habría producido en la cercanías de Clavijo, La Rioja (España) fechado el 23 de mayo del año 844 d.C. En este evento se apareció el apóstol Santiago a caballo y espada en mano, definiendo la batalla a favor de los cristianos. 
desde la reconquista allá en Granada hasta la conquista en la América andina, en donde Santiago es un guerrero, un jinete de caballo blanco y que porta espada. En la imaginación simbólica de los españoles es el salvador, el soldado y apóstol que brinda ventura en las batallas tanto en España como "mata moros" y en los Andes como el "mata indios". En el mural los trompeteros y los personajes en cabalgaduras que portan banderas y arcabuces aluden al despliegue de milicias que prefiguran acciones bélicas.

La representación tiene el sentido simbólico y mítico de exaltar la figura de Santiago, el "mata moros" de las tierras de Iberia trasladado a los confines de la geografía andina, específicamente collavina. Por lo tanto el símbolo grabado en el soporte pétreo es una imagen que alude a esa idea y remite al espectador a una realidad no tangible.

\section{c.- Interpretación del significado de la} pintura rupestre en su contexto cultural

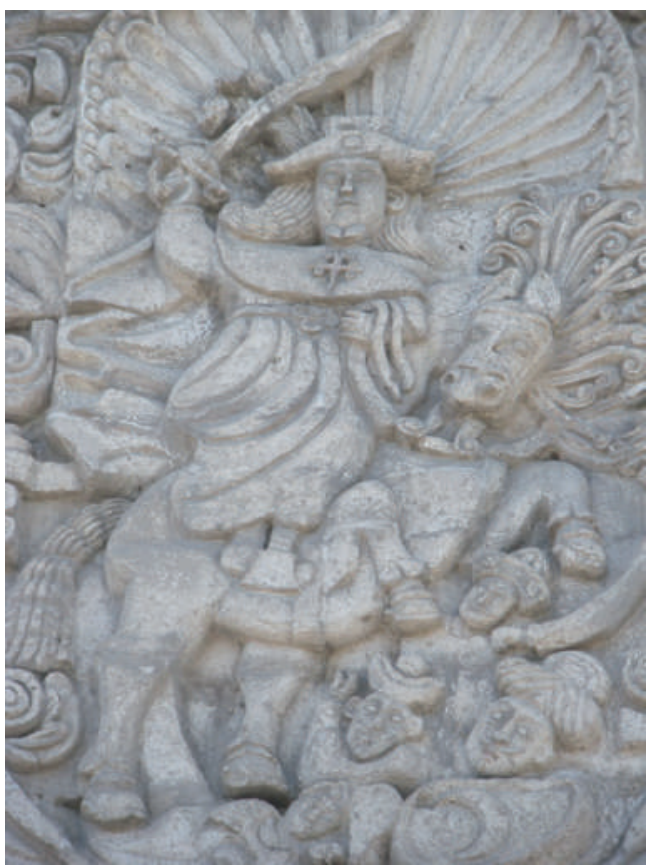

Fig.4. Detalle del apóstol Santiago. Fachada lateral de la compañía en Arequipa. intentando comprender el tiempo en que se ejecutó

La irrupción rupestre del icono de la Cruz cristiana marca la aparición de los españoles en la región. Las distintas siluetas del crucifijo, pintadas y grabadas comienzan a poblar profusamente los paneles pétreos que anteriormente eran espacio exclusivo de motivos autóctonos. El allanamiento político, económico y social de los conquistadores ibéricos en los andes del sur y especialmente en la puna, también se refleja en la superestructura y serán precisamente los símbolos de la nueva religión católica quienes se impondrán no solamente en los colosales templos coloniales de la región, sino también en la plástica rupestre. La Cruz de Cristo en sus distintas formas y tamaños, simple o provista de peana, independiente o dentro de un contexto, y, en algún caso, vinculada a insignias de ciertas órdenes militares se convertirá en un instrumento eficaz del proceso de evangelización. La inserción de las nuevas composiciones rupestres occidentales, exactamente sobre las imágenes y motivos ancestrales, consolidaron la imposición ideológica sobre el universo simbólico atávico y dejaron su impronta.

Actualmente ciertos sitios rupestres son considerados por las poblaciones rurales circunvecinas como espacios sagrados en los que desarrollan rituales y presentan ofrendas. Los conquistadores españoles en el temprano periodo colonial seguramente vieron estos actos en esos mismos parajes por parte de las poblaciones oriundas y en nombre de la extirpación de las idolatrías estamparon cruces y otros grafemas hispánicos sobre los mismos soportes pétreos.

Sin duda ésta alegoría de Santiago es la más impresionante pintura rupestre colonial de Puno. Constituye la representación simbólica de un nuevo orden cultural, económico y político instaurado en los andes. Patentiza mediante las figuras y sus atributos otro tipo de relaciones en las estructuras del poder pues las pictografías sobre ese panel de roca comunican cómo y quién detenta el poder. 


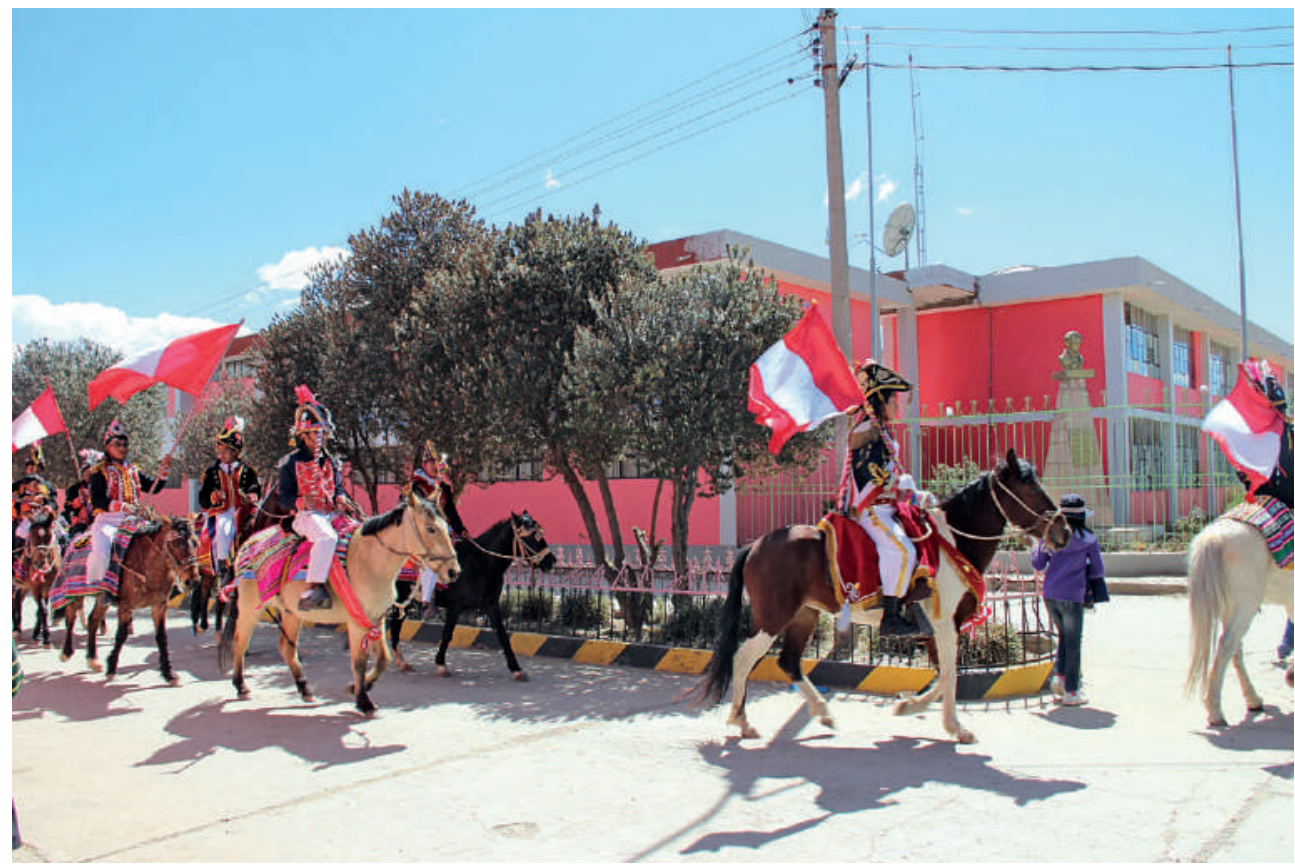

Fig.5. Los “caperos” de Santiago en la festividad de "Tata Santiago" el 25 de julio en la ciudad de Lampa.

La Cruz-espada es la divisa de la religión y de la autoridad. La figura de la caballería y los arcabuces son los insólitos instrumentos coactivos de la tutela y las trompetas y estandartes completan la parafernalia que indica el trastrocamiento del mundo andino. En resumen, el mensaje del pintor colonial es: "aquí hay un nuevo Dios, un nuevo orden y nosotros lo imponemos". Y, sin duda, constituye un tributo al Santo de la reconquista de España del dominio de los árabes y al Santo de la conquista del imperio de los incas: Santiago.

Una interrogante fundamental es ¿por qué pintaron la alegoría sobre roca y en un espacio tan inhóspito de la cordillera puneña que, situada a 4,580 $\mathrm{msnm}$, constituye una altura límite para la propia vida humana? Tenemos que ubicarnos en el contexto geográfico: prácticamente toda esta zona alta de la provincia de Carabaya es, probablemente, una de las que preserva la mayor cantidad de expresiones rupestres de la cordillera del sur del Perú: escenas de cacería de camélidos, tarucas y otros iconos andinos. Considero que los españoles, en un afán de establecer su huella impusieron este tipo de imágenes como recordatorio de su potestad y la autoridad de la devoción cristiana-católica.

La provincia de Carabaya, cuya historia precolombina, colonial y republicada es notable, actualmente es una zona minera por excelencia así como ganadera. Juega un papel importante también, su extraordinaria ubicación geopolítica como punto de paso obligatorio hacia la Amazonia, el valle de Vilcanota (Cusco) y la propia meseta del Collao. La pintura alegórica que comentamos debió convertirse en un objeto de contemplación constante, configurando una suerte de pascana para el descanso y los rituales propiciatorios de los viajeros. Repito, la ubicación estratégica del peñón al "pie del camino" por donde transitaban españoles e indios, caravaneros y acémilas, cumplió el extraordinario papel de recurso visual cuyo soporte pétreo susceptible de veneración, era un recordatorio del dominio español y cristiano sobre los andinos, una imagen al servicio del poder español y de la evangelización. 


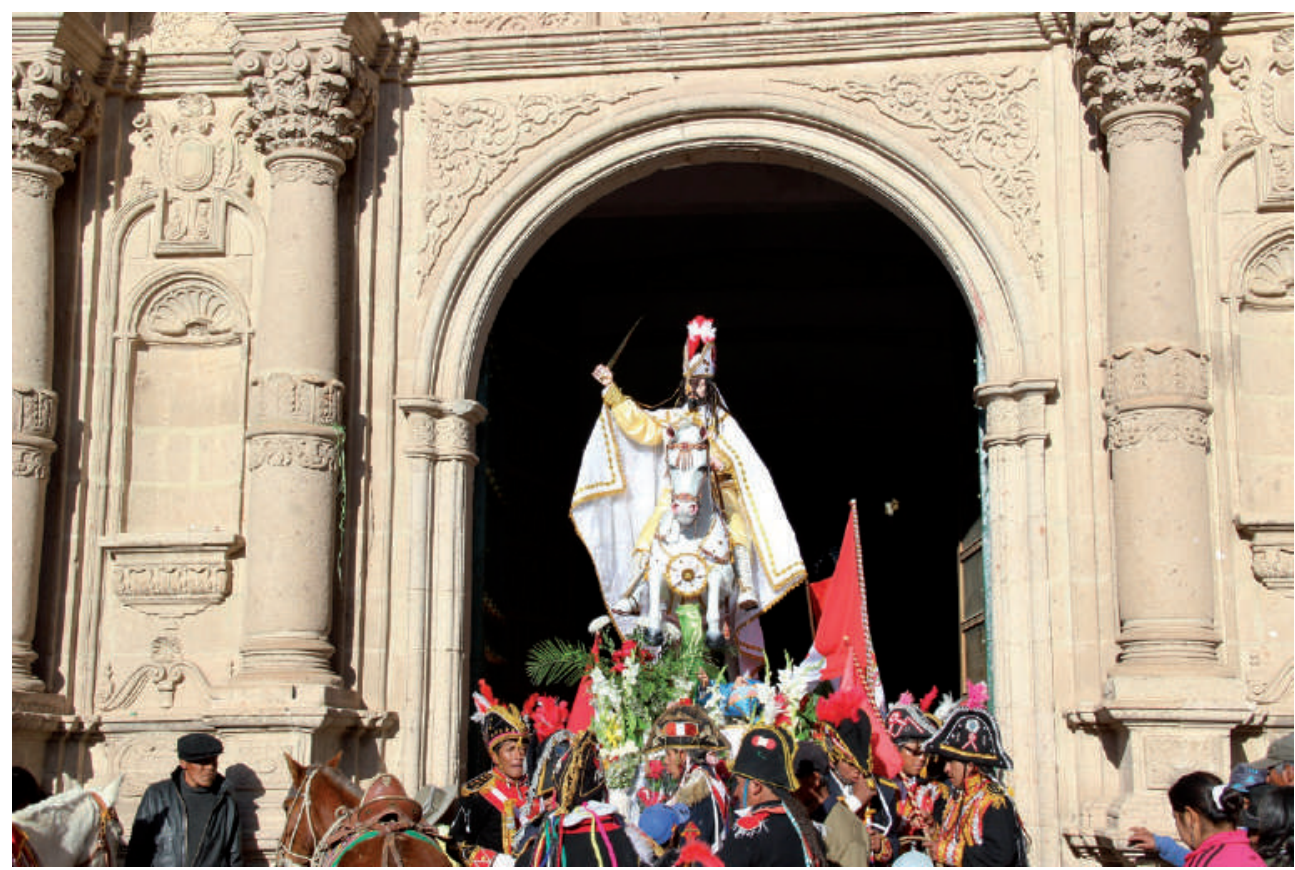

Fig.6. El apóstol Santiago en Lampa, los “caperos” le rinden pleitesía.

Si la estructura del cuadro narrativo se ubica en los primeros años del siglo XVII, sin duda alguna hace referencia a la exaltación, misticismo y fe que el santo jurado de España entraña al ser un personaje que determina el triunfo y la buena fortuna en los trajines bélicos, como sucedió en la mencionada batalla de Clavijo o como en el llamado "milagro de Sunturhuasi", en el Cusco, cuando al grito de "Santiago" y bajo una tormenta, los españoles vencieron a los indígenas, en 1536, durante el cerco de Manco II (Gisbert, 2004:28).

Finalmente, la pintura rupestre guarda relación con una escena de festividad y devoción al Santo patrono, pintada tanto por españoles, mestizos o indígenas. Si se refiere a estos últimos podría hacer referencia al culto asociado a las comunidades indígenas con el Dios Illapa $^{2}$ el trueno y el ganado, el santo del mundo rural por antonomasia. Actualmente en Puno, varios pueblos de la región festejan su santoral el 25 de julio.

Una mirada desde la etnografía, nos permite constatar la "permanencia" o "vigencia" de la escena pictográfica en una festividad el pueblo de Lampa, ubicado en el corazón del altiplano puneño, precisamente cada 25 de julio. Me refiero a la fiesta patronal de Santiago Apóstol o de "Tata Santiago" como lo denomina el habla popular. Los pobladores básicamente del sector rural conocidos como "caperos" (figs. 5 y 6) se engalanan y "apropian" de la figura del Santo Patrón, pues desfilan gallardos montados en sus potrillos y vestidos con atuendo militar: llevan en la cabeza un sombrero o birrete "falucho" cubierto parcialmente con cintas de la bicolor nacional. Visten levita ceñida negra que termina en dos puntas y bordados en el pecho, cuello y mangas y una banda roja y blanca que les cubre el torso, así como botones de metal dorado, pantalón blanco con cintas rojiblancas, escarpines y botas. Portan en la mano enguantada espada y bandera nacional que ellos denominan (wantera y

2 Diego Gonzales de Holguín en el vocabulario de la lengua Quechua dice Rayo = Illapa; Arcabuz = Illapa. 


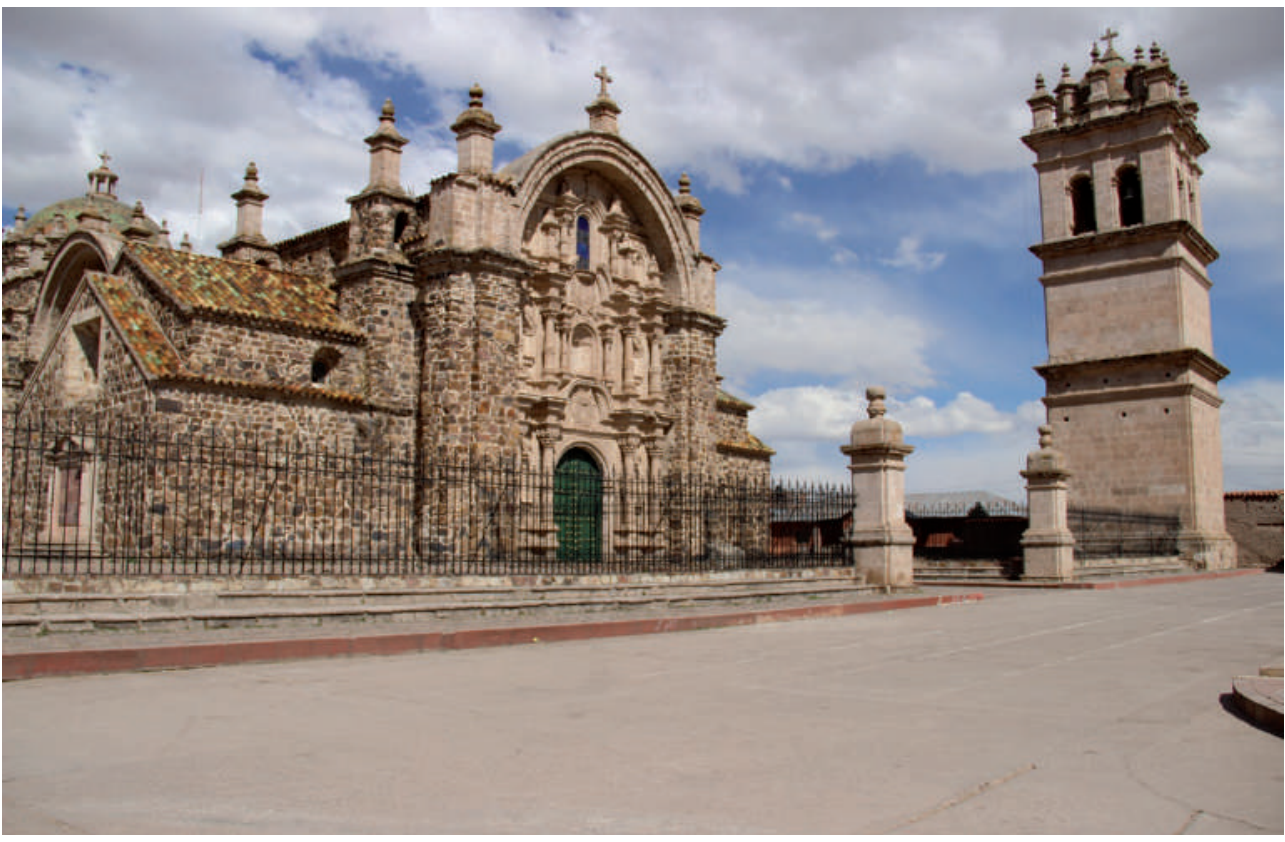

Fig.7. Portada de los pies y torre exenta del Templo "Santiago Apóstol” de Lampa-Puno.

cuchillo). Tras ellos viene su banda de "guerra" denominados "pitubanda" músicos andinos que apuran el paso "marcial" soltando al aire festivo el sonido de sus "pitus" (flauta traversa), tambores y triángulos. La presencia de los "caperos" estos personajes y jinetes únicos, quizá sin saberlo evocan la batalla de Clavijo, del Santiago de Compostela, del Santiago "mata moros", del Santiago "mata indios", pues con su indumentaria y coreografía evocan el nombre, el santo y seña del pueblo de Lampa en la urdimbre de lo andino y colonial. Considero que los "caperos" en la trayectoria del tiempo y la fiesta han cambiado parcialmente la vestimenta ya que actualmente se asemeja a la indumentaria de los soldados de las huestes libertadoras del general San Martín; de hecho la independencia nacional de 1821 también dejó su huella.

Como es sabido muchos pueblos de América y del Perú llevan el nombre de Santiago. Por citar dos ejemplos en Puno: Santiago de Pupuja y Santiago de Pomata. Precisamente a uno de los pueblos más simpáticos del Collao, desde la presencia de los españoles en la región, se le advocó el nombre de "Santiago de Lampa". Un extraordinario documento proporcionado por el músico e intelectual lampeño Arturo Vizcarra Zea a quien escribe, el cual lo recibió, a su vez, de Julio Macedo Pastor, en el pueblo de Palca, establece la impronta del Apóstol Santiago en aquel pueblo. El texto es el siguiente:

En el pueblo de Santiago de Lampa provincia y corregimiento de este nombre en 27 días de mes de Octubre de 1616. Don Mateo de Suero y Gonsales juez nombrado para la visita de tierras de esta provincia, la de Azángaro y de Paucarcolla por el señor Licenciado Don Juan Bravo de Rivero del Consejo de su Majestad y su oidor Alcalde de Corte de su Real Audiencia de Charcas y juez privativo de la referida visita venta, y composición de tierras de su distrito por el Rey Nuestro Señor (que Dios Guarde) $)^{3}$.

3 Archivo personal. Las negritas son nuestras. 
No esta demás decir que la monumental estructura pétrea del templo de Lampa esta también advocada al apóstol y que en el frontis principal está grabado el atributo de Santiago el Mayor el apóstol preferido de Cristo o el escudo de la orden militar de los Caballeros de Santiago (fig.7).

\section{Referencias}

Chávez, A., Salas, G., Gutiérrez, E., \& Cuadros, J. (1997). Geología de los cuadrángulos de Corani y Ayapata, hojas 28-u y 20-v. Boletín INGEMMET, A 90, 36-67.

Gisbert, T. (2004). Iconografía y mitos indígenas en el arte (3rd ed.). La Paz: Gisbert.

Gonzales Holguín, D. (1989). Vocabulario de la lengua general de todo el Perú llamada lengua Qquicchua o del Inca. Lima: UMSM.

Hostnig, R. (2010). Carabaya, paisajes y cultura milenaria. Lima: Biblos.
Pulgar Vidal, J. (1996). Geografía del Perú. Las ocho regiones naturales. Lima: Peisa.

Ramos, R. \& Apaza, M. (2013). Arte rupestre en Puno. Registro y catalogación (1st ed.). Puno: UNA.

San Cristóbal, A. (2006). Puno esplendor de la arquitectura virreinal (1st ed.). Lima: Peisa.

Strecker, M. (2016). Arte rupestre de la región del Lago Titicaca (Perú y Bolivia) (1st ed.). La Paz: Plural.

Recibido el 4 de setiembre de 2016. Aceptado el 11 de octubre de 2016. 